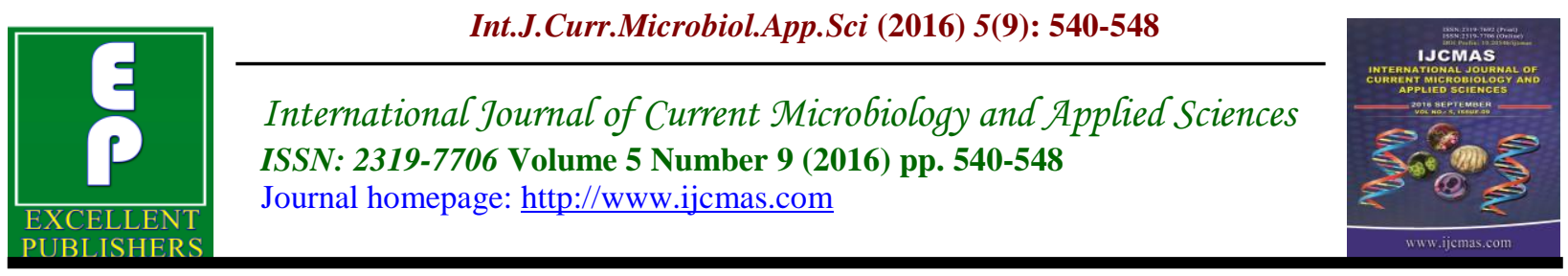

Original Research Article

http://dx.doi.org/10.20546/ijcmas.2016.509.060

\title{
Screening for Dermatophytosis and other Skin Infections in Orphanages in and around Kalaburgi, India
}

\author{
M. Ravish Kumar ${ }^{\text {* }}$, Pavan Kumar², Prashant Parandekar ${ }^{3}$, \\ Rajhans Nagarkar ${ }^{4}$ and Praveen Kumar Doddamani ${ }^{5}$
}

${ }^{1}$ Assistant professor, Department of Microbiology, ESIC Medical College, Gulbarga, India

${ }^{2}$ MBBS Student, ESIC Medical College, Gulbarga, India

${ }^{3}$ Professor \& HOD, Department of Microbiology, ESIC Medical College, Gulbarga, India

${ }^{4}$ Associate professor, Department of Microbiology, ESIC Medical College, Gulbarga, India

${ }^{5}$ Assistant professor, Department of Microbiology, ESIC Medical College, Gulbarga, India

*Corresponding author

\section{A B S T R A C T}

Keywords

Screening, dermatophytosis, orphanages, $\mathrm{KOH}$ mount and fungal culture.

\section{Article Info}

Accepted:

20 August 2016

Available Online:

10 September 2016
Dermatophytosis is a common contagious skin disease caused by fungi known as Dermatophytes. Dermatophytosis is most common in tropical and subtropical countries. Kalaburgi is a district in Karnataka where the hot and humid climate favours the fungal infections. Dermatophytoses in orphans reflects the status of health hygiene and personal cleanliness of a community. The present study aimed at screening Dermatophytosis and evaluating the pattern of the same. 175 orphans were screened for dermatophytosis. Samples were collected with aseptic precautions and processed for $\mathrm{KOH}$ mount and fungal culture (Sabarauds dextrose agar and Dermatophyte test medium). The isolates were confirmed by performing LPCB mount. Among 175 orphans 6(3.42\%) were positive by KOH mount and culture (Sabarauds dextrose agar\& DTM) had 4(2.28\%) positivity. The prevalence of other diseases such as Pityriasis alba, Tinea versicolor, Scabies and Pediculosis capitis were $6.8,2.2,12.5,0.5 \%$ respectively. This study detects epidemiological pattern, predominant organism causing dermatophytosis and other skin infections in orphanages.

\section{Introduction}

Superficial mycoses are infections of skin, hairs and nails caused by dermatophytes, yeasts and non-dermatophyte molds. Among these, dermatophytes are responsible for the largest number of cases. Dermatophytes are divided into three genera: Trichophyton, Epidermophyton and Microsporum. Distribution of the dermatophytes varies with the geographical area and course of time (Agarwal et al., 2014).
The high humidity and temperature provides a fertile ground for their abundant growth (Sen et al., 2006).

Dermatophytes can survive solely on outer cornified layers of the skin. The ability of certain fungi to adhere to particular host arises from numerous mechanisms and host factors, including the ability to adapt to the human body (Tainwala et al., 2011). 
India is a large subcontinent with remarkably varied topography, situated within the tropical and subtropica belts of the world. Its climate is conducive to the acquisition and maintenance of mycotic infections Since dermatophytosis occurs most frequently during the monsoon, the present study was planned during this period (Singh Suman et al., 2003).

Accccording to World Health Organization (WHO), the prevalence rate of superficial mycotic infection worldwide has been found to be $20-25 \%$, that of india is found to be 21-22\% (Lakshmanan et al., 2015; Suman Saurabh et al., 2013).

Surveillance for fungal infections is important to define their burden and trends, to provide the infrastructure needed to perform various epidemiological and laboratory studies, and to evaluate interventions (Bassiri-Jahromi et al., 2009).

The aim of the study was to know the prevalence of cutaneous fungal infection and other infections especially Dermatophytosis. By knowing the prevalence we can estimate the treatment problem and take measures to prevent the spread of infection.

\section{Materials and Methods}

Source of the study: The study was conducted on students present in orphanages in and around kalaburgi

Study period: The study was conducted for a period of 2 months from June to July 2015

Inclusion criteria: All the children present in the orphanages between the age group of 5 to 20 years were screened for Dermatophytosis.

Exclusion criteria: Students on antifungal treatment for dermatophytosis.

Consent refusal
Study design: Prospective cross sectional study

Study site: Orphanages in and around kalaburgi

Duration of study: 2 months (june \& july)

\section{Methodology}

The present study was conducted in 5 orphanages in kalaburgi. Ethical consideration was obtained from the institution. Sample size was 175 . We had prepared a proforma which included the data regarding the socio-demographic information such as age, sex, Address, history of presenting illness, General physical examination and local examination which was filled by the investigator. Each child was be examined in bright ambient light to search for disease of the skin and its appendages. The findings are recorded in the same form. If there are suspected dermatophytosis like scaly lesions on skin, alopecia, discolouration/pitting nails the specimen were collected under aseptic precautions with blunt end of sterile blade for skin lesions, hairs were plucked, nail clippings were collected and immediately sent to microbiology laboratory for further processing. In the laboratory If the specimen is skin scrapings/hair/nail clippings, $\mathrm{KOH}$ mount was performed and simultaneously inoculated on Saborauds dextrose agar and Dermatophyte test medium. The cultures were incubated at room temperature for 28 days. The tubes were observed for growth daily and if found, the day on which appearance of colony was noted and LPCB mount were done to identify the fungi. If there was no growth upto 28 days the specimen was considered to be negative Finally the data was gathered using the proforma clinical examination, and culture details are compiled, coded and entered in excel spread sheet. And this data was tabulated and were analyzed using chi 
square test to study the association between various factors. $\mathrm{P}$ value $<0.05$ will be considered statistically significant. $\mathrm{P}$ value < 0.001 is highly significant. The data will be represented as number and percentage.

\section{Results and Discussion}

Out of 175 screened orphan children Males were were about $80(45.71 \%)$ and females were 95 (54.28\%). (Table 1)

Dermatophytes was highly significant with prevalence of $3.43 \%$. Prevalence of other skin diseases like Pyteriasis alba, T.versicolor and scabies were $6.86 \%$, $2.29 \%, 12.5 \%$ respectively. (Table 2 and Table 3)

Among 6 dermatophytes 6 were positive by $\mathrm{KOH}$, 4 were positive by Sabaraud's dextrose agar and Dermatophyte test medium.(Table 4)

Among 4 grew on culture media 3 were Trichophyton mentagrophytes and 1 was Trichophyton verrucosum. (Table 5)

The present study covered the spectrum of dermatophytosis in a specialised population group of orphanages. The study included 175 children between age group 5-20 years among which Males were 80 and females were 95 in number.

The prevalence of dermatophytosis in our study was $3.42 \%$.The low prevalence might be due to the target population and age group we have selected. There are hardly any studies of dermatophytosis on orphanages.

The $\mathrm{KOH}$ mount had prevalence of $3.42 \%$ in comparison with Culture (Sabarauds dextrose agar\& DTM) which had $2.28 \%$.

The prevalence of other diseases such as Pityriasis alba, Tinea versicolor, Scabies and Pediculosis capitis were 6.8, 2.2, 12.5, $0.5 \%$ respectively.

Among 6 dermatophytic infections 3 were Tinea capitis, 2 were T.corporis and 1 was T.cruris. This shows that prevalence of Tinea capitis was more due to overcrowding, poor hygiene and other factors.

The prevalence of overall fungal infections in our study was $12 \%$ which explains high prevalence due to environmental factors like semi-arid region, hot and moist climate.

Other disease apart from fungal infection was mainly comprised of Scabies and Pediculosis capitis which had 12.5 and $0.5 \%$ prevalence and the disease was observed in government orphanage. The incidence was increasing in that place due to inappropriate treatment and awareness about the disease.

Table.1 Age and gender distribution

\begin{tabular}{|l|l|l|l|l|l|}
\hline \multirow{2}{*}{$\begin{array}{l}\text { Age } \\
(\text { Yrs })\end{array}$} & \multicolumn{2}{l|}{ Male } & \multicolumn{2}{l|}{ Female } & Total \\
\cline { 2 - 6 } & No. & $\mathbf{\%}$ & No. & \% & No. \\
\hline $\mathbf{5 - 1 0}$ & 20 & 45.45 & 24 & 54.55 & $\mathbf{4 4}$ \\
\hline $\mathbf{1 0 - 1 5}$ & 48 & 55.81 & 38 & 44.19 & $\mathbf{8 6}$ \\
\hline $\mathbf{1 5 - 2 0}$ & 12 & 26.67 & 33 & 73.33 & $\mathbf{4 5}$ \\
\hline Total & $\mathbf{8 0}$ & $\mathbf{4 5 . 7 1}$ & $\mathbf{9 5}$ & $\mathbf{5 4 . 2 9}$ & $\mathbf{1 7 5}$ \\
\hline
\end{tabular}




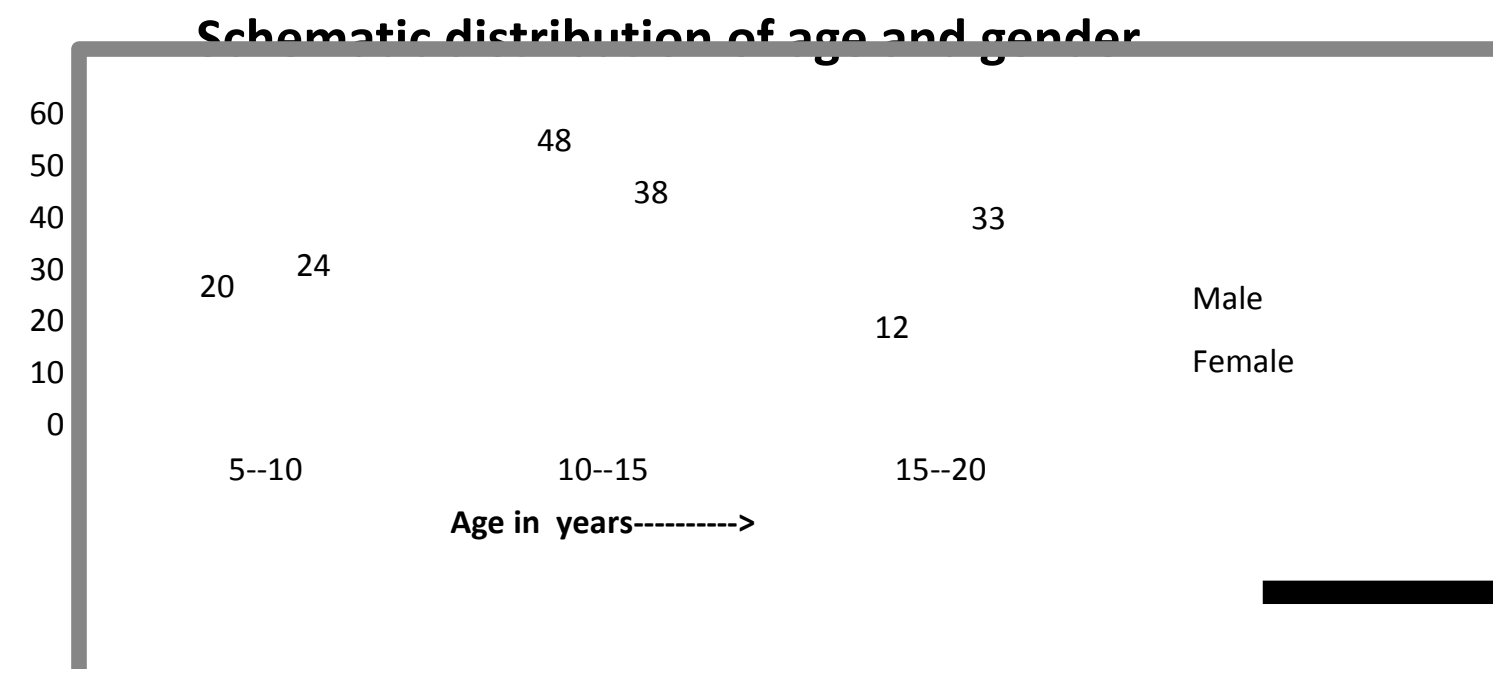

Table.2 Distribution of diseases according to age

\begin{tabular}{|c|c|c|c|c|c|c|}
\hline \multirow[t]{2}{*}{ Age } & \multicolumn{6}{|c|}{ Diseases } \\
\hline & Dermatophytes & P.alba & T.versicolor & Scabies & $\begin{array}{l}\text { Pediculosis } \\
\text { capitis }\end{array}$ & Total \\
\hline $5-10$ & 0 & 2 & 3 & 15 & 01 & 21 \\
\hline $10-15$ & 1 & 8 & 1 & 05 & 00 & 16 \\
\hline $15-20$ & 5 & 2 & 0 & 02 & 00 & 07 \\
\hline Total & 6 & 12 & 4 & 22 & 01 & 44 \\
\hline Percentage & 3.43 & 6.86 & 2.29 & 12.57 & 0.57 & 25.1 \\
\hline P-Value & $\begin{array}{l}0.004 \\
\text { Highly } \\
\text { significant }\end{array}$ & $\begin{array}{l}0.45 \\
\text { Insignificant }\end{array}$ & $\begin{array}{l}0.06 \\
\text { Insignificant }\end{array}$ & $\begin{array}{l}0.0001 \\
\text { Highly } \\
\text { Significant }\end{array}$ & $\begin{array}{l}0.22 \\
\text { Insignificant }\end{array}$ & \\
\hline
\end{tabular}


Table.3 Prevalence of skin diseases.

\begin{tabular}{|l|l|}
\hline Skin diseases & Prevalence \% \\
\hline Dermatophytosis & 3.43 \\
\hline Pyteriasis alba & 6.86 \\
\hline Tinea versicolor & 2.29 \\
\hline Scabies & 12.57 \\
\hline
\end{tabular}

Table.4 Comparison of $\mathrm{KOH}$ and culture on SDA and DTM

\begin{tabular}{|l|l|l|l|}
\hline Chemical agent & KOH & SDA & DTM \\
\hline $\begin{array}{l}\text { No. of positive } \\
\text { cases }\end{array}$ & 6 & 4 & 4 \\
\hline
\end{tabular}

Table.5 Prevalence of dermatophytes

\begin{tabular}{|l|l|}
\hline Trichophyton mentagrophytes & 3 \\
\hline Trichophyton verrucosum & 1 \\
\hline \multicolumn{2}{|l|}{ Total } \\
\hline
\end{tabular}

Table.6 Correlation between clinical and mycological findings

\begin{tabular}{|l|c|c|}
\hline Clinical type & T.mentagrophytes & T.verrucosum \\
\hline Tinea capitis & - & 1 \\
\hline Tinea corporis & 2 & - \\
\hline Tinea cruris Total & 1 & - \\
\hline & 3 & $\mathbf{1}$ \\
\hline
\end{tabular}

Table.7 Incidence of isolation of dermatophytes according to clinical condition.

\begin{tabular}{|l|l|l|}
\hline Clinical type & Number of KOH positives & Number of culture positives \\
\hline Tinea capitis & 3 & 1 \\
\hline Tinea corporis & 2 & 2 \\
\hline Tinea cruris & 1 & 1 \\
\hline
\end{tabular}

Comparision of prevalence of dermatophyte infections with other studies

\begin{tabular}{|c|c|}
\hline Studies & Prevalence(\%) \\
\hline Study at Baroda ${ }^{4}$ & 44.62 \\
\hline Study at Tehran ${ }^{7}$ & 25.86 \\
\hline JC mohanthi et al ${ }^{8}$ & 36.19 \\
\hline A S chowdhari et al ${ }^{9}$ & 38.31 \\
\hline Present study & 3.4 \\
\hline
\end{tabular}


The prevalence of dermatophytosis in our study group was $3.4 \%$ which is lower than the studies mentioned in the above table.
The reason for low prevalence might be the target population we have selected and the age

Comparision of prevalence of fungal infections with other studies

\begin{tabular}{|l|l|}
\hline Study & Prevalence \\
\hline Singh-beena $^{4}$ & 60.83 \\
\hline Shashindokth & \\
\hline Sharma et $^{7} \mathbf{l}^{10}$ & 34.9 \\
\hline Thakare et $^{\text {al }}{ }^{11}$ & 6.9 \\
\hline Present study & \\
\hline & 5.6 \\
\hline
\end{tabular}

The prevalence of fungal infection in our study was $12 \%$ which was comparable and

higher than the studies conducted by Sharma et al., and Thakare et al.

Comparison of prevalence of other skin diseases with other studies

\begin{tabular}{|c|c|}
\hline STUDY & PREVALENCE (\%) \\
\hline Sharma et al ${ }^{10}$ & 27.3 \\
\hline Thakare $e t a l^{11}$ & 18.59 \\
\hline Balai et al ${ }^{13}$ & 34.8 \\
\hline Present study & 13.1 \\
\hline
\end{tabular}


Our study showed $13.1 \%$ prevalence in other skin diseases mainly composed of scabies and Pediculosis capitis cases.

Comparision of different species of Trichophyton with other studies
The present study had less number of dermatophyte isolates. Among them $75 \%$ (three isolates) were Trichophyton mentagrophytes and $25 \%$ (one isolate) was T.verrucosum. Our study was comparable with study conducted by Sanjeev and at Tehran.

\begin{tabular}{|c|c|c|c|}
\hline Study & T.mentagrophytes & T.verrucosum & T.rubrum \\
\hline Lakshmanan et $a l^{5}$ & $14.5 \%$ & - & $17 \%$ \\
\hline Study at Baroda ${ }^{4}$ & $17.2 \%$ & - & $73 \%$ \\
\hline Study at Tehran ${ }^{7}$ & $19.9 \%$ & $6.6 \%$ & - \\
\hline Study by Sanjeev $^{12}$ & $25 \%$ & $10.5 \%$ & - \\
\hline Present study & $75 \%$ & $25 \%$ & - \\
\hline
\end{tabular}
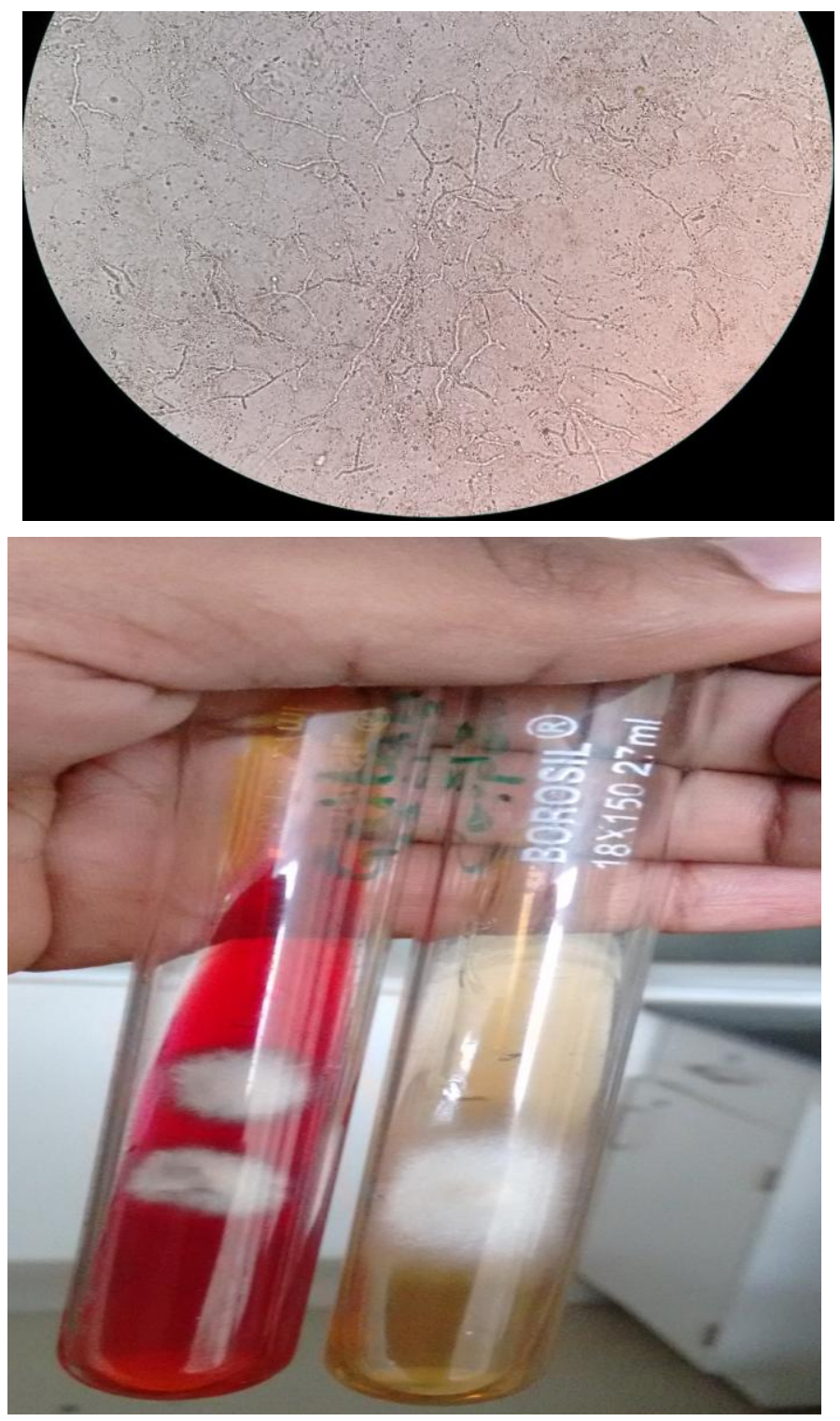


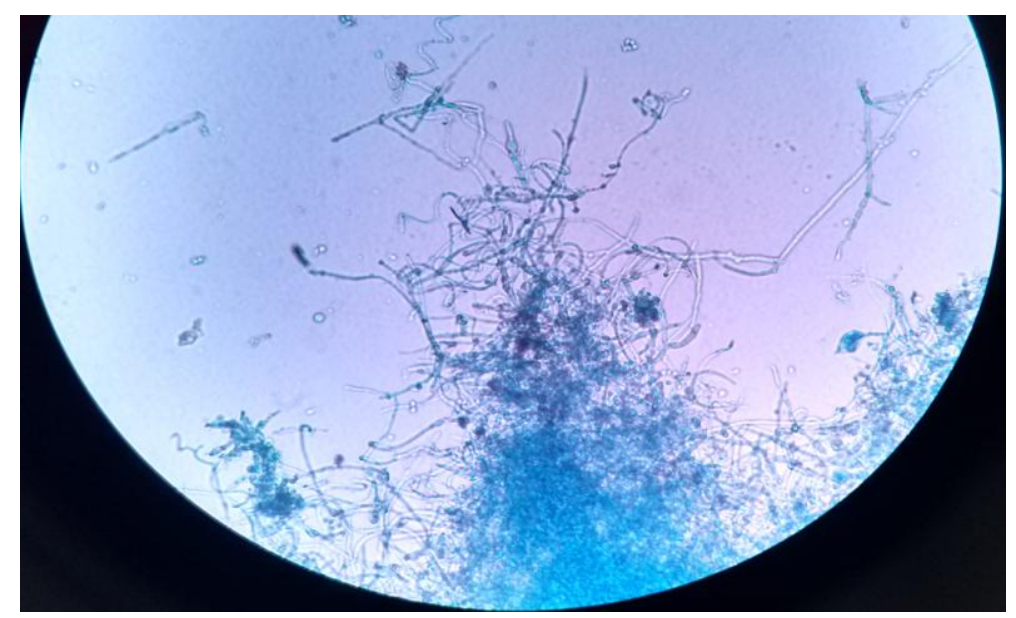

In conclusion, our study was conducted on orphanages which is a neglected group on which not much study has been done. Though the dermatophytes detected were less, commonest was Tinea capitis followed by Tinea corporis and Tinea cruris. The prevalence of fungal infections was comparatively high, scabies accounted more number of cases among overall skin infections in our study.

Apart from studying the prevalence of disease we have to look at factors responsible for the same and conduct educational programme creating awareness about the common contagious skin illnesses and how to prevent from getting infection. Regular checkup by the doctors on this under priviliged population can be recommended to government authorities with follow up.

\section{Acknowledgement}

Indian Council of Medical Research (ICMR), New Delhi

This study was done as a part of ICMR Project (STS)

\section{References}

Agarwal, U.S., Saran, J., Agarwal, P. 2014. Clinico-mycological study of dermatophytes in a tertiary care centre in northwest India. Indian $J$. Dermatol. Venereol. Leprol., 80: 194.

Balai, M., Khare, A.K., Gupta, L.K., Mittal, A., Kuldeep, C.M. 2012. "Pattern of pediatric dermatoses in a tertiary care center of south west Rajasthan." India J. Dermatol., 57(4): 275-278.

Bassiri-Jahromi, S., Khaksari, A.A. 2009. Epidemiological survey of dermatophytosis in Tehran, Iran, from 2000 to 2005. Indian J. Dermatol. Venereol. Leprol., 75: 142-7.

Chowdhary, A.S. 1986. Study Of Dermatophytoses At Aurangabad Orissa. Indian J. Med. Microbiol., 4: 229-232

Lakshmanan, A., Ganeshkumar, P., Mohan, R.S., Hemamalini, M. 2015. Epidemiological and clinical pattern of dermatomycoses in rural India. Indian J. Med. Microbiol., 33: 134-136.

Mohanty, J.C., Mohanty, S.K., Sahoo, R.C., Sahoo, A. 1998. Incidence of dermatophytosis in Orissa. Indian $J$. Med. Microbiol., 16: 78-80.

Sahal, S., Mishra, D. 2011. Change in spectrum of dermatophytes isolated from superficial mycoses cases: First report from Central India. Indian J. Dermatol. Venereol. Leprol., Vol 77, Issue 3, 335-336. 
Sen, S.S., Rasul, E.S. 2006. Dermatophytosis in Assam. Indian J. Med. Microbiol., 24: 77-8.

Shrama, S., Bassi, R., sodhi, M.K. 2012. "Epidemology of dermatoses in children and adolescents in Punjab, India." J. Pakistan Assoc. dermatologists, 22(3): 224-229.

Singh Suman, Beena, P.M. 2003. Profile of dermatophyte infections in Baroda Indian J. Dermatol. Venereol. Leprol., 69(4): 281-283.

Suman Saurabh, Swaroop, K., Sahu, Aswanthi Sadishkumar, Jibin,
C., Kakkanattu. 2013. Screening for skin diseases among primary school children in a rural area of Puducherry. Indian J. Dermatol. Venereol. Leprol., 79: 268.

Tainwala Ram, Sharma, Y.K. 2011. Pathogenesis of dermatophytoses. Indian J. Dermatol., 56(3): 259-261.

Thakare, S., Sing, A., Madnani, A. and Lakhar, B. 2013. "Scenario of pediatric dermatoases in rural population of central India." Global J. Dermatol. Venereol., 1: 7-10.

\section{How to cite this article:}

Ravish Kumar, M., Pavan Kumar, Prashant Parandekar, Rajhans Nagarkar and Praveen Kumar Doddamani. 2016. Screening for Dermatophytosis and other Skin Infections in Orphanages in and around Kalaburgi. Int.J.Curr.Microbiol.App.Sci. 5(9): 540-548. doi: http://dx.doi.org/10.20546/ijcmas.2016.509.060 